\title{
A Common Left-Right Scale for Voters and Parties in Europe
}

\author{
James Lo \\ SFB 884, University of Mannheim, L13, 17, 68131 Mannheim, Germany \\ e-mail:lo@uni-mannheim.de \\ Sven-Oliver Proksch \\ Department of Political Science, McGill University, 855 Sherbrooke Street West, \\ Montreal, Quebec H3A 2T7, Canada \\ e-mail: so.proksch@mcgill.ca (correspondingauthor) \\ Thomas Gschwend \\ Department of Political Science, University of Mannheim, A 5, 6, D-68131 Mannheim, Germany \\ e-mail: gschwend@uni-mannheim.de \\ Edited by Jonathan Katz
}

\begin{abstract}
This article presents a scaling approach to jointly estimate the locations of voters, parties, and European political groups on a common left-right scale. Although most comparative research assumes that crossnational comparisons of voters and parties are possible, few correct for systematic biases commonly known to exist in surveys or examine whether survey data are comparable across countries. Our scaling method addresses scale perception in surveys and links cross-national surveys through new bridging observations. We apply our approach to the 2009 European Election Survey and demonstrate that the improvement in party estimates that one gains from fixing various survey bias issues is significant. Our scaling strategy provides left-right positions of voters and of 162 political parties, and we demonstrate that variables based on rescaled voter and party positions on the left-right dimension significantly improve the fit of a cross-national vote choice model.
\end{abstract}

\section{Introduction}

Comparative research on elections and party competition is unthinkable without comparable measures of the ideological positions of voters and political parties. A large body of research attempts to quantify positions for the most salient left-right dimension of party competition. Such estimates are typically based on data from election surveys, which ask voters to place themselves and various national political parties on a left-right scale. However, comparisons between voters and parties on the basis of such data are complicated in systematic ways, notably by perceptual bias within single surveys and across countries. We propose an approach that corrects for these issues, allowing voter and party positions to be placed on a common cross-national left-right scale.

Voter surveys complement alternative approaches for measuring party positions based on expert surveys or election manifestos because they allow the study of voter-party interactions for the main

\footnotetext{
Authors' note: This article was awarded the 2012 Gosnell Prize for Excellence in Political Methodology. The authors are grateful to Jae Jae Spoon and Ken Benoit for providing replication materials and helpful comments, and to Jonathan Slapin and Catherine de Vries for helpful suggestions. Also, the authors thank Dominic Nyhuis and Steffen Zittlau for excellent research assistance. Previous versions of this article were presented at the PIREDEU Final User Community Conference in Brussels, November 18-19, 2010, the Seminar Series of the Department of Political Science at the University of Houston, December 2010, the Biennial Conference of the European Union Studies Association in Boston, March 3-5, 2011, and at the Annual Meeting of the Midwest Political Science Association in Chicago, April 12-15, 2012. Replication materials are available at the Political Analysis Dataverse, http://dx.doi.org/10.7910/DVN/23113 (Lo, Proksch, and Gschwend 2013, Replication data for: A common left-right scale for voters and parties in Europe. http://dx.doi.org/10.7910/DVN/23113 IQSS Dataverse Network [Distributor] V1 [Version]).
} 
dimension of party competition as captured by the left-right scale. Despite this potential, the use of perceptual data to locate parties presents a number of unique problems that have not yet been resolved. One central issue is the problem of dealing with systematic respondent-level bias, a problem more commonly known in the literature as differential item functioning (Aldrich and McKelvey 1977; Brady 1985; Palfrey and Poole 1987; King et al. 2004; Alvarez and Nagler 2004). Stated differently, if a respondent believes that party A lies to the left of party B, there are multiple ways this idea can be expressed - on an eleven-point left-right scale, parties A and B could be placed at 1 and 2 , or at 4 and 8, respectively. Secondly, biases in scale perception may also manifest themselves at the cross-national level. More specifically, if respondents in France place party $\mathrm{A}$ at 4 and respondents in Bulgaria also place party $\mathrm{B}$ at 4 on the same eleven-point scale, does this necessarily imply that party A and party B occupy the same ideological position on the left-right scale?

Our scaling approach provides a solution to these issues. First, we correct for systematic perceptual biases of survey respondents within countries to place parties and voters on the same national scale. Subsequently, we rescale country-specific estimates into a common cross-national left-right space by exploiting the fact that national parties affiliate with political groups in the European Parliament. Estimates of uncertainty are then generated through a nonparametric bootstrap. Using data from the 2009 European Election Study (EES 2011), our scaling strategy provides party positions for 162 parties together with their standard errors, and comparable voter placements and left-right positions for the European political groups.

Our study proceeds as follows. First, we discuss common problems that appear in cross-national studies of voters and parties and subsequently present our model, which combines earlier work by Aldrich and McKelvey (1977) and Groseclose, Levitt, and Snyder (1999). We validate our estimates for the 2009 EES in several ways. First, we examine party and voter locations in the United Kingdom and demonstrate that rescaled estimates are not only substantively consistent with prior expectations but also significantly improve the model fit in a spatial model of voting with valence. Second, we test the validity of party position estimates against those available from expert surveys and find that the two correlate highly. Third, we combine rescaled voter and party positions and replicate a cross-national study of individual government defection in European Parliament elections (Hobolt, Spoon, and Tilley 2009). The use of rescaled estimates improves the model and yields results that are in line with theoretical expectations. We conclude with a discussion of directions for future research.

\section{Scaling Survey Respondents onto a Common Scale}

The division into left and right is a well-established dimension of party competition and frequently used as a proxy for the most salient political conflicts in Europe. Although the concrete meaning of left and right may differ across countries and time (Benoit and Laver 2006), the literature typically considers it a valid approximation of a super issue. This is confirmed by studies using survey data that demonstrate that a majority of individuals in democracies have political orientations that can be placed on a left-right scale (Dalton, Farrell, and McAllister 2011). Moreover, voter and party positions on the left-right dimension are variables that are central to the majority of cross-national studies of electoral behavior and party competition (e.g., Powell 2000; Adams, Merrill, and Grofman 2005; De Vries 2007; Duch and Stevenson 2008; Hobolt, Spoon, and Tilley 2009; Ezrow 2010; Duch, May, and Armstrong 2010; Dalton, Farrell, and McAllister 2011). Although current applications using left-right distances assume that cross-national comparisons of voters and parties on this dimension are possible, there is so far no consensus of how scholars should generate comparable voter and party positions.

\subsection{Comparison of Voter and Party Positions}

Comparing voter and party positions lies at the core of comparative studies of party competition, party systems, representation, and political behavior. At least four different approaches are commonly used. Although all approaches combine respondents' self-placement (in Europe using the classic eleven-point left-right response-scale survey instrument) with some left-right party 
position measure, these approaches differ in how they operationalize party positions in order to calculate the distance between respondents and parties.

The first approach combines self-placements of respondents with party positions derived from expert surveys (e.g., Benoit and Laver 2005; Hobolt, Spoon, and Tilley 2009). There are at least two issues that complicate a valid comparison of voter and party placements. Often, expert surveys on party positions and mass surveys operate with different response scales, and scholars attempt to enable comparability by linearly transforming the respective endpoints of the different scales onto one another. Moreover, mass and expert surveys are administered at different points in time. Scholars at least implicitly assume that these time inconsistencies are no threat to the comparability of voter and party placements; that is, parties do not change position between those time points.

The second approach combines self-placements of mass survey respondents with party positions derived from content analysis of party programs, such as data from the Comparative Manifesto Project. In addition to the challenge of operating with different scales, as discussed above, there is another threat to the comparability of voter and party placements using this approach. Voters most likely perceive parties for "what they are rather than for what they do" (Mair and Mudde 1998, 224) - namely, that party positions generated from a content analysis of what parties promise to do in terms of policy might be different from how voters perceive them.

The third approach measures party locations using either mean self-placements or mean voter perceptions of parties, and proceeds to calculate distance measures from individual voters by comparing those party positions with self-placements. The use of mean party placements has been a common approach in the political behavior literature since Markus and Converse (1979) because placements are measured on the same response scale. Nevertheless, mean party placements can be anywhere on the scale, whereas respondents are forced into discrete values on the response scale (Westholm 1997, 871). Moreover, there is no consensus in the literature on which set of respondents one should use to calculate a party's mean placement. Some studies rely on the (entire or a sub-)sample of all respondents (e.g., Alvarez and Nagler 2004; Peterson 2009; Golder and Stramski 2010; Bawn and Somer-Topcu 2012), or merely on those respondents that can be identified as voters (e.g., Rabinowitz and Macdonald 1989; Erikson and Romero 1990; Macdonald, Listhaug, and Rabinowitz 1991). Others subset their data differently each time when calculating a position and calculate the party mean either based on all partisans (e.g., Rehm and Reilly 2010; Bawn and Somer-Topcu 2012) or on all voters of that party (e.g., Westholm 1997; Duch, May, and Armstrong 2010).

A fourth approach combines respondent self-placements and individual perceptions of party positions from the same survey onto a common scale, rather than calculating distances from a party position that is assumed to be constant across respondents. Spatial theories of party competition and political behavior require that an individual voter compares her position on the underlying common scale with her perception of the parties' position on that scale (Enelow and Hinich 1984; Hinich and Munger 1994; Blais et al. 2001; Adams, Merrill, and Grofman 2005; Kedar 2005; Calvo and Hellwig 2011). Proponents of the fourth approach thus question the assumption of a fixed party position where perceptual variability across respondents is interpreted as measurement error. Simply put: How should individuals base their decision on, say, the mean perceived party position; that is, on information they do not have? Therefore, scholars use the perceived variability of party positions across respondents to extract meaningful information.

To sum up, scholars employ different approaches to compare left-right placements of voters and parties. It is unclear, however, to what extent such placements are comparable within and across countries. We address this question by focusing on two distinct issues: scale perception in surveys within a single country and bridging observations for cross-country comparisons.

\subsection{Scale Perception Issues in Surveys}

In comparative survey research, scholars typically do not test to what degree the usage of a scale on which they place voters and parties is actually comparable across respondents. The lack of interpersonal comparability or differential item functioning leads to scale perception biases that can yield faulty results. This becomes an issue if respondents understand the "same" question in vastly 
different ways (Aldrich and McKelvey 1977; Brady 1985; Palfrey and Poole 1987; Alvarez and Nagler 2004; King et al. 2004). To illustrate how scale perception issues might affect voter placements, suppose there are two voters who are asked to place three British parties, Labour, Liberal Democrats, and Conservatives on an eleven-point (0-10) left-right response scale. The first voter places Labour at 1 , the Liberal Democrats at 3, and Conservatives at 4 . The second voter locates Labour at 0 , the Liberal Democrats at 5, and Conservatives at 10. Both voters rank the parties identically, but each perceives the scale with very different levels of "bias" and "stretch." The first voter sees little ideological distance between the three major parties and believes they all lie far to the left. In contrast, the second voter sees an enormous amount of distance between the three parties without the leftward bias of the first voter. In other words, the two voters might perfectly agree on where the parties stand; yet, their interpretation of the response scale leads them to placements that differ. The same response bias may apply to their own placement on the scale (Aldrich and McKelvey 1977; Alvarez and Nagler 2004).

We address this problem using an intermediate solution developed by Aldrich and McKelvey (1977, hereafter AM), which estimates the positions of parties and voters in a common issue space within each country. Since the actual positions of parties are assumed to be the same for all respondents, they serve as anchors to recover comparable party and voter positions. Applying the AM procedure, we assume that voters have perceptions of party positions that are linearly distorted in an unknown, but estimable, way. This approach has previously been used to fix withinsurvey scale perception biases in surveys (Palfrey and Poole 1987; Saiegh 2009; Poole et al. 2011). Nevertheless, comparisons of scales across countries may still be invalid.

\subsection{Cross-Country Comparisons}

As ideological positions are latent quantities, direct comparisons across countries are generally difficult to make. Many estimators designed to produce comparable ideological estimates across countries and institutions exist, though most are tailored to the American context. One common approach is to conduct a single estimate of multiple political actors that are connected through expressed preferences to common political phenomena. Although this is not the approach we take, it is responsible for much of the recent literature on this topic. ${ }^{1}$

We instead adopt a different approach, first producing separate estimates by country before transforming each set of estimates into a common space using a common interinstitutional/ intertemporal variable. This approach is especially prominent in the separation-of-powers literature on the United States - for example, Bergara, Richman, and Spiller (2003) map different ideology measures for the US Congress and the Supreme Court into a joint space using observed percentliberal votes as bridging observations. Similarly, Groseclose, Levitt, and Snyder (1999) scale the US legislature by first obtaining ideology measures for each separate Congress and Senate, then transform them into a common space under the assumption that each legislator's mean preference parameter remains constant across time. Other studies identify bridge legislators directly and exploit the fact that they serve across multiple institutions to scale all legislators from those institutions into a common space (Poole 2005; Shor, Berry, and McCarty 2010) or use common surveys as a cross-state anchoring device (Shor and McCarty 2011).

Rather than assuming that respondents from different countries interpret the response scales presented to them in an identical manner, we leverage an additional source of data, using the membership of national parties in their respective political groups inside the European Parliament as bridging observations. The key idea justifying the use of European political group membership to connect nationally estimated scales onto a common European space is that national parties choose their party group affiliations largely on the basis of left-right ideological conflict —an

\footnotetext{
${ }^{1}$ Recent examples include Jessee (2009) and Bafumi and Herron (2010), who ask survey respondents for their preferences on preselected Senate legislation, allowing them to place survey repondents and legislators into a common space. See Poole and Rosenthal (1997), Bailey (2007), Gerber and Lewis (2004), and Treier (2010) for other examples of this approach.
} 
assumption that enjoys substantial empirical support from Hix, Noury, and Roland (2007) and McElroy and Benoit (2010).

\section{The Model}

Our scaling approach relies on standard questions found in many comparative surveys today. Using voter self-placements and their placements of political parties on the left-right scale from the 2009 EES (EES 2011), ${ }^{2}$ our model estimates the ideological locations of parties in two stages. In the first stage, we apply a model developed by Aldrich and McKelvey (1977) to obtain ideological estimates of national parties and voters. These estimates correct for individual-scale perception differences (differential item functioning) and are comparable within countries. Using these estimates, we then apply a technique adopted from Groseclose, Levitt, and Snyder (1999) to rescale those estimates into a common European left-right scale using European Parliament group memberships as bridging observations. This generates voter and party placements that are crossnationally comparable. Additionally, we recover ideological estimates of the European political groups on the same scale as auxiliary estimates that prove useful in validating our estimates. Finally, uncertainty estimates of party positions are generated via a nonparametric bootstrap.

\subsection{Correcting for Individual Left-Right Scale Perception Differences}

In the first stage, we estimate party locations within each country using the left-right placement question in the 2009 EES (Egmond et al. 2010; EES 2011), which asks respondents to place various national parties on a $0-10$ scale. $^{3}$ Assume there are $J$ parties in a country to be placed on the scale by $N$ respondents. These parties each occupy a (true) latent position $\theta_{j}(1 \leq j \leq J)$. Each respondent $i(1 \leq i \leq N)$ has a latent perception of the $j$ th party, defined as the true position with error distributed following standard Gauss-Markov assumptions; that is, $\theta_{i j}=\theta_{j}+\epsilon_{i j} .{ }^{4}$. However, surveys record only the observed perception on the left-right scale of party $j$ by respondent $i, Y_{i j}$. AM allow for differential item functioning to be accounted for by assuming that each individual has separate perceptual bias and stretch parameters $\alpha_{i}$ and $\beta_{i}$. These parameters distort the reports of respondent $i$ 's placement of party $j$ such that

$$
\theta_{j}+\epsilon_{i j}=\theta_{i j}=\alpha_{i}+\beta_{i} Y_{i j} .
$$

Under this assumed model of behavior, the AM procedure jointly estimates the individual bias and stretch vectors $\hat{\alpha}_{i}$ and $\hat{\beta}_{i}$ and the party locations $\hat{\theta}_{j}$ by minimizing the sum of squared residuals across all respondents and parties such that

$$
\sum_{\forall i, j} \epsilon_{i j}=\sum_{\forall i, j} \hat{\alpha}_{i}+\hat{\beta}_{i} Y_{i j}-\hat{\theta}_{j}
$$

subject to the model identification constraint that the estimated party positions $\hat{\theta}$ have mean zero and unit sum of squared distances from the mean. The AM technique is applied separately to each country survey from the EES and produces estimates of left-right party locations that are comparable within each country. It also produces estimates of each respondent's latent location on the same ideological scale, $\theta_{i}$, by transforming self-reported placements, $X_{i}$, with their individually estimated bias and stretch parameters, such that

$$
\hat{\theta}_{i}=\hat{\alpha}_{i}+\hat{\beta}_{i} X_{i}
$$

\footnotetext{
${ }^{2}$ Replication materials are available at the Political Analysis Dataverse, http://dx.doi.org/10.7910/DVN/23113.

${ }^{3}$ The AM technique assumes continuous scales. Readers who wish to employ similar techniques on data of a clearly ordinal nature are advised to consult Quinn (2004) for ordinal alternatives.

${ }^{4}$ Principally, this means independently distributed errors that are normally distributed with mean 0 .
} 
These jointly scaled scores of voters and parties can significantly improve our position estimates, an argument we pursue further when applying our scores to a simple spatial model of voting with valence. $^{5}$

\subsection{Correcting for Cross-Country Differences}

The aim of the second stage is to make voter and party locations comparable across countries. This is not possible with the first procedure alone, because although each country will likely have a different mean ideological location and variance, these parameters are assumed to be identical across countries under AM. Let $\alpha_{k}$ be a country-specific shift parameter. Now suppose there are two countries that separately have $\alpha$ values of 0 and 0.5 , but identical stretch parameters $\beta_{k}$. This implies that the mean of the parties on the left-right scale in the second country lies 0.5 units to the right of the mean position in the first country, so failure to account for this shift (i.e., by assuming $\alpha=0$ for both countries) will bias our estimates of all parties in the second country by 0.5 units. In practice, this would mean that, say, the German party mean position is assumed to be the same as the French party mean position, whereas in reality the party system in France may be shifted toward the left compared to the party system in Germany.

Facilitating cross-national comparisons therefore requires that each country's set of party locations be rescaled into a common space. To do this, we exploit the political group affiliations of each party in the European Parliament following the 2009 elections as bridging observations. Using the previously estimated location of parties as data, $\left(\hat{\theta}_{j k m}\right)$, we assume

$$
\hat{\theta}_{j k m}=\psi_{k}+\gamma_{k} \theta_{m}+\epsilon_{j k m} \quad \forall j, k, m,
$$

where $\theta_{j k m}$ is the position of party $j\left(1 \leq j \leq J_{k}\right)$ in country $k(1 \leq k \leq K)$ belonging to European political group $m(1 \leq m \leq M)$ as recovered in the first-stage AM procedure. These scores are assumed to be functions of country-specific shift and stretch parameters $\psi_{k}$ and $\gamma_{k}$, and the latent position of their corresponding European political group $\theta_{m}$. We further assume that the error term $\epsilon_{j k m}$ is distributed normally with mean zero and variance $\sigma^{2}$, which allows estimation of our key parameters of interest through maximization of the likelihood function:

$$
L\left(\psi_{k}, \gamma_{k}, \theta_{m} \mid \hat{\theta}_{j k m}\right)=\prod_{j=1}^{J_{k}} \prod_{k=1}^{K} \prod_{m=1}^{M} \phi\left(\frac{\hat{\theta}_{j k m}-\psi_{k}-\gamma_{k} \theta_{m}}{\sigma}\right) .
$$

Identification of the model requires the constraining of two parameters. We accomplish this by constraining $\psi_{K}=0$ and $\gamma_{K}=1$ for a specific country, thus effectively placing all parties on the ideological scale of that country. ${ }^{6}$ Estimation of the parameters of interest is similar to the procedure proposed by Groseclose, Levitt, and Snyder (1999). ${ }^{7}$ Following estimation of all parameters, common-scale party positions are calculated by transforming each first-stage score as follows:

$$
\hat{\theta}_{j k}^{T}=\frac{\hat{\theta}_{j k m}-\hat{\psi}_{k}}{\hat{\gamma}_{k}} .
$$

Similarly, each respondent's self-placement on the common scale is calculated analogously as

$$
\hat{\theta}_{i k}^{T}=\frac{\hat{\theta}_{i k}-\hat{\psi}_{k}}{\hat{\gamma}_{k}}
$$

\footnotetext{
${ }^{5}$ Notably, Palfrey and Poole (1987) use Monte Carlo simulation to show that the AM procedure recovers party locations well, even if errors are heteroskedastic over stimuli.

${ }^{6} \mathrm{As}$ in all scaling problems, identification is strictly relative, so the choice of country is completely arbitrary. We ran our model by initially rescaling positions into the Bulgarian party space, and we again $z$-transform all the scores to have mean zero and unit variance. The final estimates are not affected by the choice of which country's ideological scale is chosen for the initial rescaling.

${ }^{7}$ We elaborate on the differences between our method and Groseclose, Levitt, and Snyder (1999) in the supplementary appendix.
} 


\subsection{Generating Uncertainty Estimates}

Following Efron and Tibshirani (1994), we are able to generate standard errors for our estimates using a nonparametric bootstrap. Bootstrapping is done by resampling survey respondents from the survey with replacement and re-estimating both the national-level party estimates and the crossnational rescaling on the resampled data. We repeat this process over one hundred iterations. Note that this simulates the uncertainty present in the respondent sampling process, but assumes no uncertainty in our knowledge about the European group affiliation of each party. We therefore assume that parties have sorted themselves into an ideologically compatible European group - an assumption that is consistent with prior research (Benoit and McElroy 2007; Hix, Noury, and Roland 2007) and appears to be reasonable in most cases when we inspect our estimates. ${ }^{8}$

\section{Results}

We now discuss the model fit and present key results from the estimation that demonstrate that the rescaling yields more accurate estimates of voter and party placements from the surveys on a left-right scale. In our first example, we examine the nationally rescaled party and voter placements and apply them to a spatial model of valence in the United Kingdom. We demonstrate that model fit significantly increases using the rescaled left-right scale. In our second example, we examine the estimated party positions. Although using data from the 2009 EES allows us to estimate positions for many more parties than currently available in expert surveys, we show that for those parties that appear in both our estimation as well as expert surveys, the ideological estimates exhibit high convergent validity. Finally, in a third example we replicate an individual-level model of government defection at European elections using our rescaled scores. Using those scores improves the model fit and has a substantive impact on one of the key explanatory variables in this model.

\subsection{Estimation Summary}

The data we use are eleven-point left-right self-placements of voters and of different parties from the 2009 EES. ${ }^{9}$ Table 1 examines the summary statistics of our country-level estimates, the first part of the rescaling procedure. One immediate item to note is that a substantial fraction of the countrylevel samples disappear due to missing-data issues. Recall that respondents only remain in the sample if they place themselves and all other parties on the left-right scale. Although the 2009 EES surveyed approximately one thousand respondents in each country, as many as 716 respondents get dropped in countries such as Bulgaria. This problem is likely to be particularly acute in countries where respondents are asked to place parties that are difficult to locate, resulting in survey nonresponse. Nevertheless, samples in all countries are sufficiently large for estimation. ${ }^{10}$ Each country-level estimation also identifies a set of survey respondents with negative weights - that is, respondents who see parties in a "mirror image" space where parties on the left and right are reversed. Palfrey and Poole (1987) demonstrate that these are largely individuals with very low levels of political information. Building on this idea, they hypothesize that one reasonable measure of individual-level political information is the correlation between the individual's perceived location of the parties and the scaled party locations. We constructed an information measure from respondents by applying a standard two-parameter item response model to a battery of seven political information questions in the EES, and found that our survey measure correlated with the AM-derived measure at $r=0.28$. The moderate magnitude of this relationship is largely consistent with that reported earlier by Palfrey and Poole.

\footnotetext{
${ }^{8} \mathrm{An}$ important exception to our assumption of reasonable sorting is Estonia, which we discuss in greater detail later in the article.

${ }^{9}$ This estimation is done for all countries except Malta. We omit Malta because as a two-party system, the two countryspecific parameters are uniquely identified. Due to unresolved coding issues in the data release of the 2009 EES affecting several countries, results from Belgium, Denmark, Sweden, and Spain are dropped from the joint rescaling.

${ }^{10}$ Saiegh (2009), for example, is able to estimate party locations in Costa Rica using as few as thirty-one respondents.
} 
Table 1 Overall fit of left-right scales (Aldrich-McKelvey)

\begin{tabular}{|c|c|c|c|c|c|}
\hline Country & Respondents & $\begin{array}{l}\text { Number } \\
\text { negative }\end{array}$ & Parties & $\begin{array}{l}\text { Reduction } \\
\text { in variance }\end{array}$ & $R^{2}$ \\
\hline Austria & 526 & 59 & 8 & 0.160 & 0.58 \\
\hline Bulgaria & 284 & 31 & 8 & 0.173 & 0.56 \\
\hline Cyprus & 749 & 40 & 6 & 0.092 & 0.71 \\
\hline Czech Republic & 807 & 58 & 5 & 0.095 & 0.74 \\
\hline Estonia & 453 & 87 & 6 & 0.232 & 0.57 \\
\hline Finland & 849 & 48 & 8 & 0.117 & 0.63 \\
\hline France & 611 & 28 & 8 & 0.063 & 0.73 \\
\hline Germany & 875 & 50 & 5 & 0.097 & 0.74 \\
\hline Greece & 764 & 51 & 6 & 0.127 & 0.67 \\
\hline Hungary & 583 & 12 & 7 & 0.061 & 0.76 \\
\hline Ireland & 738 & 132 & 6 & 0.699 & 0.39 \\
\hline Italy & 605 & 27 & 8 & 0.048 & 0.78 \\
\hline Latvia & 501 & 89 & 9 & 0.178 & 0.54 \\
\hline Lithuania & 334 & 84 & 10 & 0.352 & 0.43 \\
\hline Luxembourg & 601 & 27 & 8 & 0.216 & 0.53 \\
\hline Poland & 367 & 37 & 6 & 0.340 & 0.50 \\
\hline Portugal & 773 & 26 & 5 & 0.079 & 0.77 \\
\hline Romania & 357 & 166 & 7 & 1.123 & 0.30 \\
\hline Slovakia & 551 & 86 & 8 & 0.228 & 0.52 \\
\hline Slovenia & 685 & 98 & 9 & 0.173 & 0.55 \\
\hline The Netherlands & 695 & 108 & 11 & 0.136 & 0.55 \\
\hline United Kingdom & 536 & 238 & 8 & 0.566 & 0.38 \\
\hline
\end{tabular}

Notes. Negative weighted respondents are those with low political information that perceive a reversed scale. Reduction in variance measures improvement from scaled over unscaled scores, which can be interpreted as the amount of differential item functioning accounted for by the model.

Two other fit statistics provide additional guidance in interpreting our model results. The reduction in variance is a ratio of the overall variance of perceptions in scaled data, divided by the average variance in the unscaled data. Substantively, it captures the percentage of variance that is corrected when differential item functioning is accounted for. The average reduction across countries is $24 \%$, and the reductions range from approximately $112 \%$ of the variance in the original data in the case of Romania to roughly $5 \%$ for Italy. The $R^{2}$ statistic measures the percentage of variance in the scaled positions that can be explained by the left-right dimension.

\subsection{Example 1: Voters and Parties in the UK}

The summary statistics just described suggest a good statistical fit for our countries in the sample, but reveal little about the substance of those estimates. Figure 1 explores this issue by examining the estimates for the United Kingdom. On the left panel, we show the recovered party coordinates overlaid on top of a density plot of rescaled voter ideal points. We find that the three major national UK parties (Labour, the Liberal Democrats, and the Conservatives) are recovered in an order consistent with prior expectations. Three smaller parties (Plaid Cymru, the Scottish National Party, and the Greens) are all located between Labour and the Conservatives, close to the Liberal Democrats. To the right of the Conservatives are the UK Independence Party and the British National Party, also consistent with prior expectations. The procedure is therefore able to recover party locations with survey data that are highly consistent with those obtained via expert surveys (Benoit and Laver 2006; Hooghe et al. 2010). Stated differently, following the language of Campbell and Fiske (1959), our scores exhibit a high degree of "convergent validity" in the sense that they are highly correlated with expert surveys while purportedly measuring the same concept.

Although our rescaled scores exhibit good convergent validity after correcting for differential item functioning, unscaled scores do not always share the same properties. We calculate unscaled 


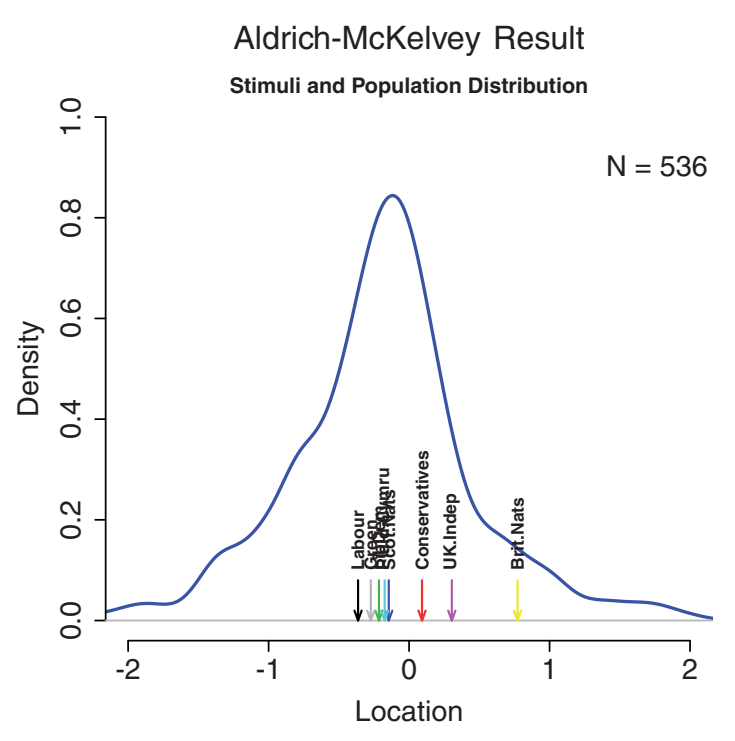

A-M estimates vs. unscaled means

Fig. 1 Results of Aldrich-McKelvey scaling for the United Kingdom, 2009. Left panel shows estimated locations of parties under AM rescaling, along with a density plot of estimated voter locations. Right panel plots estimated party locations recovered under AM to scores obtained from taking the unscaled means of party placement scores with regression line. Bars represent $95 \%$ CIs of each estimate, and size of points is proportional to vote share in 2009 European Parliament election.

party locations by simply taking the mean party placement of each party on the eleven-point scale, and plot our scaled scores against the unscaled ones with a regression line in the right panel of Fig. 1. These scores not only differ significantly, but yield a completely different configuration of parties. Although Labour, the Liberal Democrats, and the Conservatives are still aligned from left to right, there is substantial movement among all other parties. Under the unscaled means, the three smaller leftist parties (the Greens, Scottish Nationals, and Plaid Cymru) are all located to the left rather than the right of Labour. Furthermore, both the UK Independence Party and the British National Party are located to the left of the Conservatives. Expert survey data suggest, however, that the British National Party is to the right of the Conservatives (Hooghe et al. 2010). Even more distressing is the high degree of confidence that is implied by these estimates - each line on the plot captures the $95 \%$ confidence interval (CI) of each estimate, so we can reject the possibility that the UK Independence Party and the British National Party are to the right of the Conservatives. ${ }^{11}$

Although party locations recovered under AM exhibit high convergent validity with expert surveys, the rescaling technique has the additional benefit of rescaling each survey respondent onto the same scale. This allows a wide variety of theories regarding the spatial model of voting to be empirically tested (Downs 1957; Enelow and Hinich 1984). In applications of such models, the ideological distance between the voter and the party is typically a key variable of interest. We first estimate one such model here for the United Kingdom - a simple spatial model of voting with valence in one dimension.

Let $i$ denote an individual who is considering voting for party $j(1 \leq j \leq J)$. Individual $i$ has ideal point $x_{i}$, whereas party $j$ has ideal point $x_{j}$. Assuming quadratic utility, the deterministic spatial utility that voter $i$ receives for choosing party $j$ is $U_{i j}^{S}=-\left(x_{i}-x_{j}\right)^{2}$. However, we also assume that each party has a valence parameter $v_{j}$ that captures the nonspatial component of utility for each voter. The parameter $v_{j}$ can substantively be thought of as the value of the party brand that it

\footnotetext{
${ }^{11}$ Standard errors for scaled party locations are derived from a nonparametric bootstrap. For unscaled means, standard errors were calculated analytically.
} 
Table 2 Estimates of valence parameters in the UK, 2009 European elections

\begin{tabular}{lcc}
\hline & Unscaled estimate & AM estimate \\
\hline Liberal democrat valence & $0.903(0.261)$ & $0.149(0.206)$ \\
Conservative party valence & $-0.113(0.423)$ & $0.735(0.191)$ \\
UKIP valence & $0.802(0.304)$ & $0.230(0.220)$ \\
$N$ & 218 & 218 \\
Log-likelihood & -568 & -279 \\
Null log-likelihood & -578 & -288 \\
\hline
\end{tabular}

Notes. Valence for the Labour Party is omitted from estimation and fixed at 0 . Estimates represent the nonspatial utility that each respondent gets for voting for that party instead of Labour, with standard errors in parentheses. Unscaled estimates are calculated using mean party placements on the left-right scale and unscaled respondent self-placements. We observe that the model shows a substantially better find using scores obtained via the AM estimator. Null log-likelihoods are calculated from the same model with all valence parameters set to 0 .

carries in the electorate regardless of its positioning on the left-right scale or the relevance of omitted spatial components orthogonal to the left-right dimension. Following the random utility framework of McFadden (1973), we can then specify the full utility that voter $i$ gets from voting for party $j$ as the sum of the nonspatial, spatial, and stochastic utilities, or $U_{i j}=v_{j}-\left(x_{i}-x_{j}\right)^{2}+\epsilon$. If we further make the assumption that $\varepsilon$ is distributed as a Type 1 extreme value distribution, then the probability that voter $i$ chooses party $j$ among the $J$ possible party choices is

$$
\operatorname{Pr}\left(V_{i j}=1\right)=\frac{U_{i j}}{\sum_{k=1}^{J} U_{i k}}=\frac{e^{v_{j}-\left(x_{i}-x_{j}\right)^{2}}}{\sum_{k=1}^{J} e^{v_{k}-\left(x_{i}-x_{j}\right)^{2}}} .
$$

This is a conditional (multinomial) logit model with alternative and individual-specific variables, with $v_{j}$ as the parameters of interest to be estimated using $x_{i}$ and $x_{j}$ as data. The parameter $v_{j}$ is only identified in relative terms, so we constrain $v_{j}=0$ for the Labour Party. To simplify our model, we only retain voters who voted for one of the top four parties in the 2009 European election. We construct our likelihood function based on the choice model described above and present two versions of our valence estimates in Table 2 . In the unscaled estimate, $x_{i}$ is simply the self-reported left-right location of the voter, $X_{i}$, and $x_{j}$ is the mean placement of the party on the left-right scale by all voters, $\frac{\sum Y_{i j}}{N}$. In the AM estimates, we instead use the party and voter locations shown in the left panel of Fig. 1.

Our estimates of the spatial model using both sets of estimates show that the model fit using AMderived estimates is considerably better, as the maximized log-likelihood is almost three hundred points higher for a relatively small sample of $N=218$. These likelihoods are directly comparable because the two models use the same parameters. Model fits using the two different data sets also imply substantively different results-Liberal Democrats and the UKIP are estimated to have relatively powerful party brands using unscaled data, whereas the Conservatives are not. In contrast, our rescaled estimates imply that every party brand is powerful relative to Labour in the sense that they draw more votes than their spatial location alone would dictate - on a likelihood ratio test with three degrees of freedom against a null model with no valence parameters, we reject the null of no valence differences at $\alpha=0.01$. Labour's valence disadvantage in European Parliament elections relative to all other parties in the UK is consistent with theories of comparative political behavior and the notion of EP elections as "second-order" elections (e.g., Reif and Schmitt 1980) - a topic we return to in the third example. Finally, our estimates are consistent with popular portrayals of a 2009 Labour government that was deeply unpopular in the wake of the 2008 financial crisis and a resurgent Conservative and Liberal-Democrat opposition. ${ }^{12}$

$\overline{{ }^{12} \text { The supplementary }}$ appendix provides additional details for the UK example. 


\subsection{Example 2: Cross-National Party Positions}

In this section we discuss the cross-national party location estimates. These are obtained after rescaling the national party scores estimated under AM under the assumption that parties belonging to the same European political group are more likely to share similar political preferences on the left-right dimension. We begin with an examination of our estimates and check for obvious estimation patterns and outliers. Next, we discuss some properties of our estimates. We find that our rescaled estimates demonstrate convergent validity with expert surveys. We then discuss the estimates of our auxiliary shift and stretch parameters, arguing that these contribute significantly to the fit of some countries and that they are consistent with prior substantive research findings.

Figure 2 plots the distribution of party positions by European political groups using the rescaled estimates (top) and the simple mean positions from the survey (bottom). Once country-specific shift and stretch effects have been removed from the variation in party positions, the parties in the European Parliament groups look more compact than they do using simple means. Another way to compare the unscaled party mean positions with the rescaled estimates is to look at those parties that cross group lines. Specifically, we look at the two major groups in the EP, the Group of the Progressive Alliance of Socialists and Democrats (S\&D) and the Group of the European People's Party - Christian Democrats (EPP). Using unscaled positions, there are a number of S\&D parties with a position to the right of the leftmost EPP party. The same is true for parties from the EPP that are to the left of the rightmost party from the S\&D. ${ }^{13}$ However, this does not occur when we examine positions that have been rescaled using our two-step procedure. For these estimates, there are no crossovers of parties from the two major EP groups.

Figure 2 in the supplementary appendix presents the cross-national party position estimates separately for each political group and for parties that did not gain seats in the EP election or were not officially affiliated with a political group. ${ }^{14}$ In general, the level of consistency between the left-right orderings of the national parties and their European group affiliation is very high-national parties that are more left-leaning than their rivals tend to affiliate with more left-leaning European groups. Variation in ideological heterogeneity on the left-right scale across European political groups is another important feature that appears in our estimates. Notably, national parties belonging to the three left-leaning European political groups (EUL-NGL, GreensEFA, and S\&D) are much more tightly aligned (i.e., lower variance around European political group mean) than the right-leaning European political groups. This is largely expected for a Euroskeptic group like the EFD, but is more surprising for groups like ALDE. Finally, parties that are not aligned with an EP group or parties that did not win any seats in the EP elections in 2009 are displayed under the category "no affiliation." As expected, these parties span the entire scale, as they include parties from the far-left, center, and far-right of the political spectrum across Europe. ${ }^{15}$

As a simple validation of our estimates, we compare our cross-national party estimates to those from the 2006 Chapel Hill expert survey. Our estimates correlate with scores derived from expert surveys at $r=0.89$, suggesting a very high level of consistency. ${ }^{16}$ This convergent validity bodes well both for the expert survey literature as well as our estimates. Note, however, that relying on

\footnotetext{
${ }^{13}$ The S\&D parties to the right of the leftist EPP party are the following: SPÖ (Austria), DP and MSD (Cyprus), SPD (Germany), SE (Estonia), Pasok (Greece), SDP (Finland), PS (France), Labour (Ireland), LSAP (Luxembourg), PvdA (Netherlands), PS (Portugal), and Labour (UK). The EPP parties to the left of the rightmost S\&D party are as follows: KDU-CSL (Czech Republic), Unione di Centro (Italy), PSL (Poland), and UDMR (Romania).

${ }^{14}$ Scores have been $z$-transformed after rescaling to allow for easier interpretation.

${ }^{15}$ As a robustness check, we refit our model using "predicted" rather than "actual" EP group affiliations of national parties, as reported in McElroy and Benoit (2010). The authors use a conditional logit model to predict EP party group affiliations based on the distances between the parties and the groups on six policy dimensions, the position of the parties on the issue of decentralization, and party size. McElroy and Benoit's model correctly predicts membership for $79 \%$ of parties. These predicted groups were estimated with data from the $2004 \mathrm{EP}$, rather than the 2009 data that we use. Nevertheless, after fitting the model using predicted 2004 EP groups rather than actual 2009 affiliations and discarding three outliers, we find that our party position estimates are correlated at $r=0.91$.

${ }^{16} \mathrm{We}$ also correlated our scores against expert survey estimates from Benoit and Laver (2006), even though the dates of the expert survey and of the election study are seven years apart. Nevertheless, the scores correlate at $r=0.83$.
} 


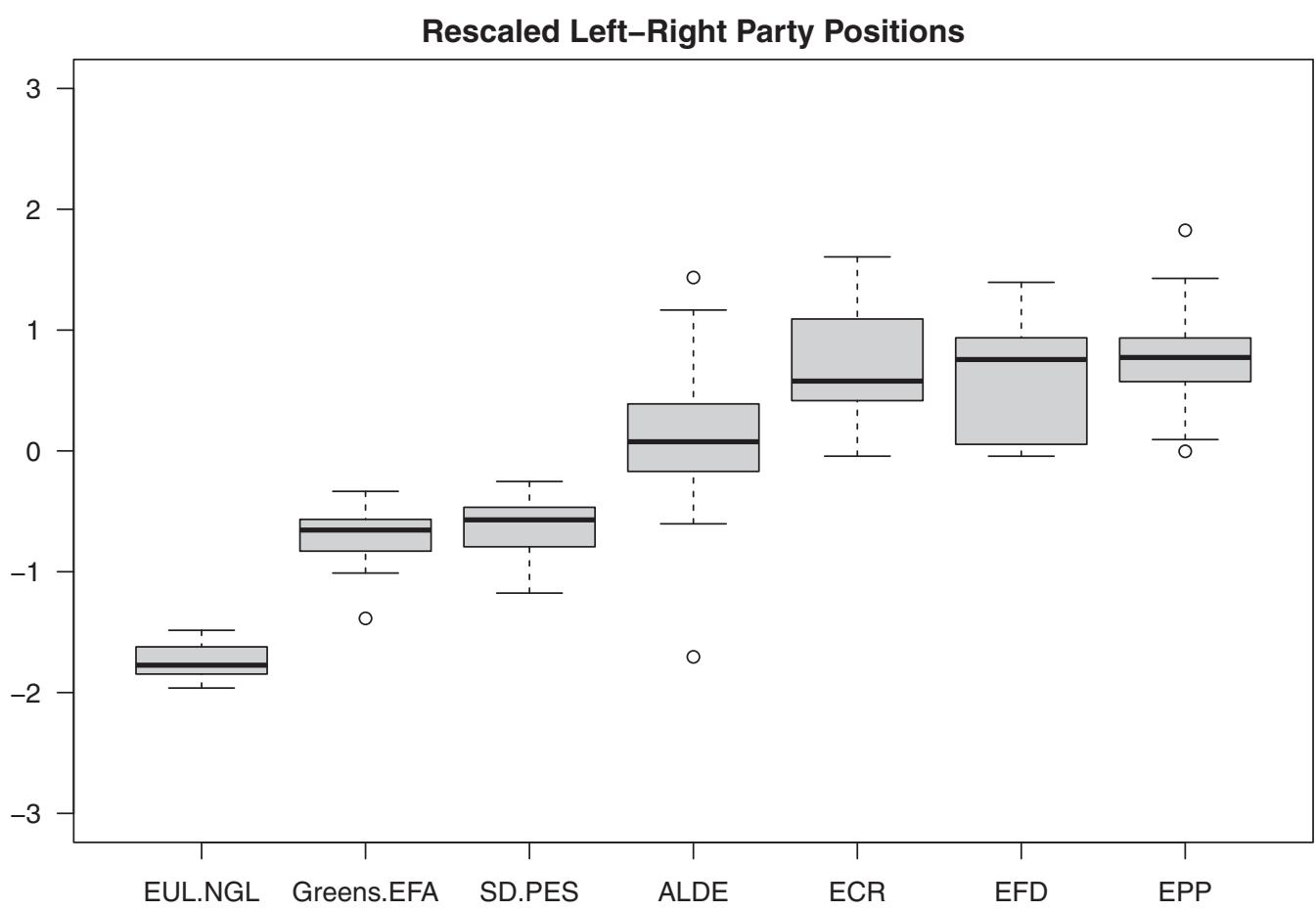

Unscaled Left-Right Party Positions

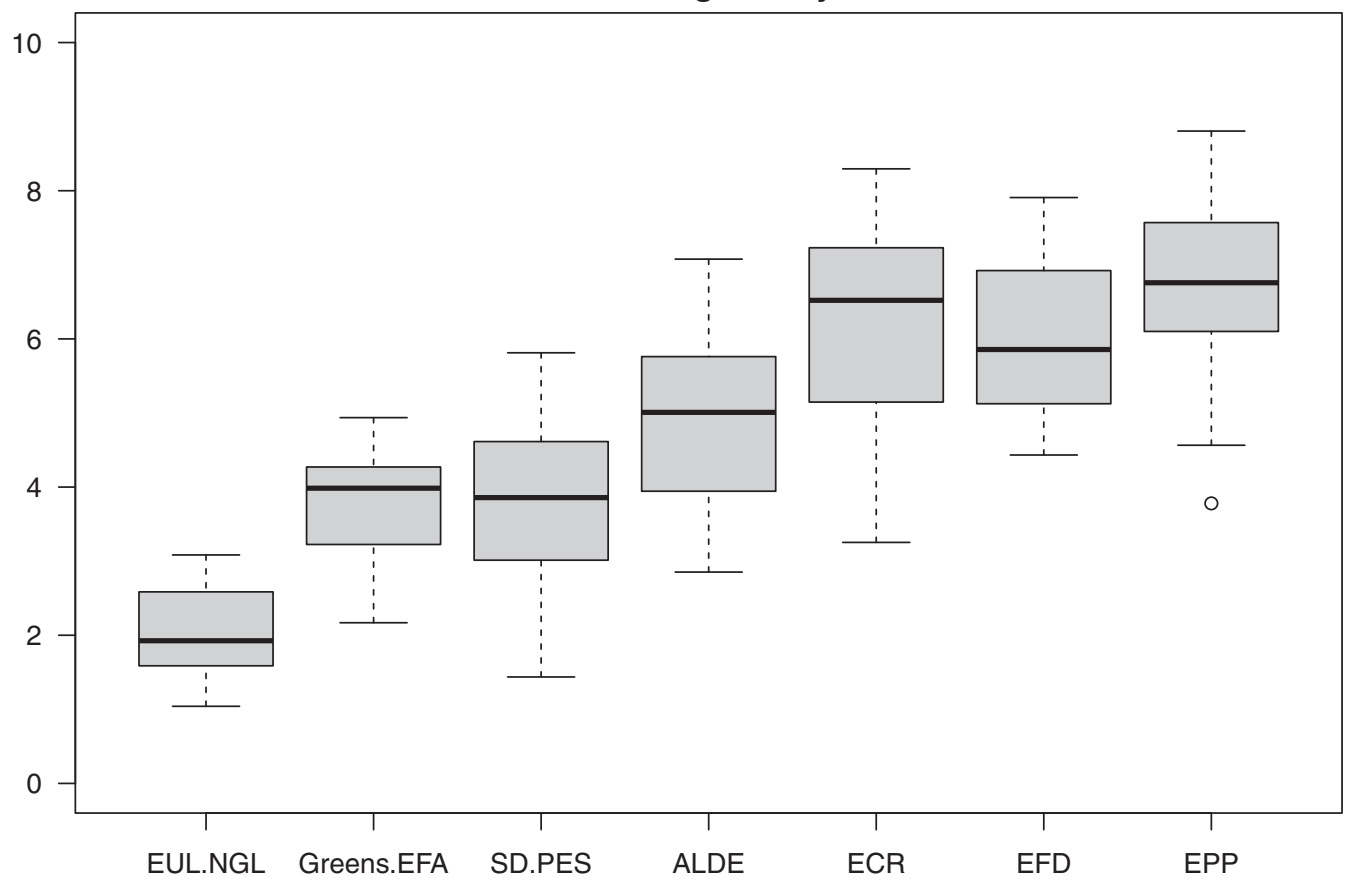

Fig. 2 Distribution of national party positions by EP group, 2009. Black lines represent medians of the national party distributions, and party groups are sorted by these medians. Thus, they do not necessarily represent the estimated EP group positions. In particular, for rescaled positions, EPG point estimates place the ECR to the right of the EPP, and the EFD to the left of the EPP. 
voter surveys can provide researchers with more party position estimates than expert surveys, as is the case in our estimation. We emphasize here that our estimates complement rather than replace expert surveys. Our technique will tend to perform well in cases where researchers wish to conduct research on left-right for a larger set of parties that are included as part of cross-national surveys but excluded from expert surveys. For example, out of the 162 parties in our data set, only 111 of those appear in the Chapel Hill data set and 114 in the Benoit and Laver expert survey. Our earlier valence example also suggests that our technique will perform well in situations where researchers wish to incorporate voter distances from parties as a variable in their analysis. Notably, our technique based on voter surveys does not generalize well to obtaining estimates of party locations on specific issue dimensions, nor does it allow us to estimate party position changes over time without making further assumptions. ${ }^{17}$

After running a nonparametric bootstrap, we find that the mean standard error of our party estimates is 0.1 . Since our rescaled estimates are $z$-transformed, this implies that our standard error spans about 0.1 standard deviations of the European left-right scale. ${ }^{18}$ The magnitude of this standard error is slightly larger but in line with standard errors for ideal points derived by other scaling procedures such as Poole and Rosenthal's DW-NOMINATE (Lewis and Poole 2004; Carroll et al. 2009).

One particular set of estimates in our data appears very unusual and requires further explanation. Estonia has two political parties that are members of the ALDE group (Eesti Keskerakond and Eesti Reformierakond), but these two parties occupy opposite ends of the political spectrum with other parties located between them, with Eesti Reformierakond located at the extreme right. Furthermore, another right-wing party (Res Publica) lies between the two extremes, to the left of Eesti Reformierakond. However, Res Publica is a member of the EPP coalition in the European Parliament. This is difficult to reconcile because although voters place Res Publica to the left of Eesti Reformierakond, their EP group memberships (EPP and ALDE, respectively) suggest that this should actually be reversed. This alignment is highly unusual, and our estimates suggest that a realignment of the Estonian parties by European political group in the future is likely. ${ }^{19}$

We also obtain estimates of the locations of the European political groups themselves. Importantly, these estimates are obtained solely as by-products of the cross-national scales - unlike the national party locations, which are in part obtained from voter placements of the parties, no voter placements of the European political groups were used to obtain these estimates. ${ }^{20}$ These estimates are, of course, substantively important to European party research, but they also serve a useful purpose in checking the validity of our estimates. More specifically, if our estimation procedure is flawed, it will not correctly recover the left-right configuration of the European political groups. We compared our estimates to the left-right placement of the groups obtained through expert surveys (McElroy and Benoit 2012). Our EP group estimates correlate with McElroy and Benoit's expert survey estimates at $r=0.91$, corroborating the validity of our approach. ${ }^{21}$

\footnotetext{
${ }^{17} \mathrm{We}$ discuss the issues associated with a possible extension of our approach to the European integration dimension in the supplementary appendix.

${ }^{18}$ The stretch of our scale is of course determined by which parties are included in the EES. Figure A-1 in the supplementary appendix shows that this space includes no less than the five major parties in each country, but if one includes small extremist parties in various countries the range of the scale would likely be considerably larger.

${ }^{19}$ We conducted an additional test to determine if our estimator was in any way driving the unusual result in Estonia, plotting our recovered party locations against the mean placement of each party across all respondents. The rank ordering of the parties was unchanged after estimation and correlated with unscaled means at $r=0.97$, but our estimator pushed the location of Eesti Keskerakond further to the left than the estimated location using unscaled means. This suggests some uncertainty about the actual location of Eesti Keskerakond, but it in no way undermines our claim that the alignment of parties in Estonia is highly irregular.

${ }^{20}$ In fact, such placements were not asked of respondents in the 2009 EES.

${ }^{21}$ We note that McElroy and Benoit's expert survey estimates the position of the small European party groups (ECR and EFD) to the right of the EPP, whereas our estimate places the EFD slightly to the left of the EPP (although the ECR remains to the right of the EPP in our estimates). From our reading of the literature, the two smaller European party groups, the ECR and EFD, appear particularly difficult to place. This is underscored by the fact that in the expert survey the ECR and EFD group positions are estimated further to the right of the most right-leaning party within their respective group. Since our estimation strategy estimates party groups and national party positions jointly, it is worth noting that such a result is impossible with our estimator.
} 
Table 3 Estimates of country shift and stretch parameters $(\hat{\psi}$ and $\hat{\gamma})$ by country, 2009 European elections

\begin{tabular}{lrl}
\hline Country & \multicolumn{1}{c}{ Shift $(\hat{\psi})$} & Stretch $(\hat{\gamma})$ \\
\hline Austria & $0.06(0.28)$ & $0.37(0.18)$ \\
Cyprus & $0.91(0.28)$ & $0.53(0.15)$ \\
Czech Republic & $0.36(0.27)$ & $0.37(0.13)$ \\
Germany & $-0.32(0.26)$ & $0.41(0.22)$ \\
Estonia & $0.49(0.20)$ & $0.41(0.16)$ \\
Greece & $0.67(0.27)$ & $0.33(0.12)$ \\
Finland & $-0.81(0.28)$ & $0.47(0.14)$ \\
France & $-0.90(0.28)$ & $0.42(0.13)$ \\
Hungary & $0.00(0.27)$ & $0.61(0.24)$ \\
Ireland & $-0.92(0.29)$ & $0.51(0.15)$ \\
Italy & $-0.22(0.22)$ & $0.51(0.18)$ \\
Lithuania & $-0.06(0.23)$ & $0.73(0.19)$ \\
Luxembourg & $-0.32(0.28)$ & $0.91(0.31)$ \\
Latvia & $-1.03(0.28)$ & $0.38(0.18)$ \\
The Netherlands & $0.05(0.27)$ & $0.66(0.22)$ \\
Poland & $0.67(0.26)$ & $0.36(0.11)$ \\
Portugal & $-0.12(0.25)$ & $0.59(0.21)$ \\
Romania & $0.25(0.22)$ & $0.73(0.21)$ \\
Slovenia & $0.10(0.28)$ & $0.97(0.25)$ \\
Slovakia & $0.16(0.21)$ & $0.39(0.12)$ \\
United Kingdom & $0.17(0.27)$ & $0.33(0.17)$ \\
\hline
\end{tabular}

Notes. $\psi$ and $\gamma$ are shift and stretch parameters facilitating cross-country comparison. Standard errors in parentheses. Omitted reference category is Bulgaria, which is fixed to have $\psi=0$ and $\gamma=1$.

Does our rescaling procedure change our estimates of party locations in a meaningful way compared to the estimation of party locations using simple means? We answer this question by examining the country-specific stretch and shift estimates and comparing rescaled party estimates with simple means. Table 3 provides estimates of the country-level rescaling parameters, $\hat{\psi}$ (shift) and $\hat{\gamma}$ (stretch). Two important patterns appear in the data. First, in eight of the twenty-one cases shown we reject the possibility that the shift parameter $\psi$ is equal to 0 at the standard 0.05 level of significance. Similarly, we reject the possibility that the stretch parameter is equal to 0 in sixteen of twenty-one cases. The key to note is that although some countries share a similar ideological distribution of parties, many do not. The substantive significance of the changes shown is quite large. Our estimate of the shift for Latvia, for example, implies that its mean party position is a full standard deviation away from that of Bulgaria, whereas our estimate of the stretch for the United Kingdom suggests that its parties span only one-third of Bulgaria's ideological range.

A second way to examine the impact of our rescaling procedure is by comparing the recovered coordinates to those obtained from the survey via simple means of left-right placements. In the context of our model, the simple means model implies not only no individual-specific bias and stretch parameters, but also a constant scale (i.e., a party rating of " 5 " in Bulgaria means the same thing as a party rating of " 5 " in the United Kingdom). Figure A-2 in the supplementary appendix visually represents this comparison with a simple scatterplot accompanied by a regression line of best fit. The two sets of estimates correlate well at $r=0.83$, compared to the earlier reported correlation of $r=0.89$ with expert scores. However, there are some extreme discrepancies between the two sets of estimates. Chief among these is our rescaled scores of the British National Party. Our estimates rank the BNP the most right-wing of the 162 national parties in our data set. However, estimates using simple means suggest that the British National Party is much more mainstream, with 64 of the 162 parties lying to the right of the BNP. Substantively, we view this to be highly unlikely and take this to be further evidence in favor of our technique. 
Summarizing our results, we provide evidence that measurement strategies such as simply taking mean party placements have lower validity than our scaling strategy that maps voters and parties on a common left-right scale. In the following section, we demonstrate the extra leverage we gain from analyzing party and voter placements on the left-right dimension in a cross-national framework. ${ }^{22}$

\subsection{Example 3: Explaining Government Defection in European Elections}

Existing measurement strategies that combine survey with party position data from expert surveys or manifestos require strong assumptions for within- and cross-country comparisons that are rarely questioned. Yet, it is quite likely that individual scale-perception biases and differential item functioning undermines the comparability and, therefore, the validity of those measurement strategies. Mapping voters and parties of different countries onto the same left-right dimension should facilitate empirical tests about the effect of the relative distances between parties and voters on political behavior. We expect first-difference effects based on our scores to be stronger than for alternative approaches that simply assume comparability. In the following, we employ our scores to explain voting defection from national government parties in European Parliament elections, extending an existing vote-choice model for European elections (Hobolt, Spoon, and Tilley 2009) to the 2009 EES.

Hobolt, Spoon, and Tilley (2009) test at the individual level the argument that European elections are second-order national contests (Reif and Schmitt 1980) that are determined by domestic factors such as distances on the left-right dimension between voters and parties and satisfaction with governmental economic performance. Additionally, they argue that European issues play a role in EP elections. Using previous European Election Studies from 1999 and 2004, Hobolt, Spoon, and Tilly provide evidence that voters who voted for a governmental party at the preceding national election are more likely to defect from this party in the next EP election the greater the distance from this party is on the issue of European integration.

We replicate their baseline defection model to determine, first, to what degree their conclusions carry over to 2009 and second, what the consequences are of using rescaled positions of voters and parties instead of the unscaled scores derived from expert and voter surveys. Hobolt et al. run a hierarchical logit model predicting defection as a function of domestic factors (government approval, assessment of economy), individual-level controls (age, social class, strength of partisanship), as well as two policy distance variables (see Hobolt, Spoon, and Tilley [2009] for further details on how those variables are coded). According to their theory, respondents should consider the EU-dimension in addition to the left-right dimension in choosing whether to defect from a previously supported government party. The distance variables are measured as absolute differences between a respondent's self-placement (from the EES survey) and the position of the government party (from the Benoit and Laver [2006] expert survey) that the respondent voted for in the preceding national election.

Table 4 in the supplementary appendix provides an overview about the number of observations, the share of defectors, as well as the parties in government across all countries in the estimation sample. In order to compare the estimation results across different measures, we restrict the sample to those respondents for which we are able to generate a distance on the left-right dimension using the original measurement strategy and using our rescaled scores. ${ }^{23}$ Finally, we only include those respondents who place themselves as well as all the respective national parties on the left-right dimension. This leaves us with $N=3937$ observations to estimate the government defection model.

Table 4 presents our results. The first two columns report the published results of Hobolt, Spoon, and Tilley (2009). Our replication results for 2009 are shown in columns 3 and 4. The

\footnotetext{
${ }^{22}$ For interested readers, the supplementary appendix includes another validation through a comparison of the party system compactness measure developed by Alvarez and Nagler (2004).

${ }^{23}$ For more details about estimation sample, we refer the reader to the supplementary appendix.
} 
third column presents the model based on the measurement strategy originally employed by Hobolt et al., whereas the last column reports the results based on our comparable left-right scores. The row for the left-right distance variable is highlighted in gray. First, the results show that the impact of domestic factors on the probability to defect from a governmental party largely applies to 2009 as well. Respondents who are satisfied with the national economy have a lower propensity to defect from the governing party they voted for in the previous national election, but this effect is only marginally significant. In contrast, respondents who approve of the government have a significantly lower defection probability, as do voters who identify with governing parties. Regarding the ideological distances, Hobolt et al. found mixed results. They established consistent effects for EU integration and left-right distance between voters and parties only for the 2004 European election, but not for the 1999 election. Although we cannot reproduce their effect for the EU dimension for 2009, we do find a positive effect of the distance between voters and parties on the left-right dimension on the defection probability. This effect, however, is only significant when using our rescaled scores.

Table 4 shows, as expected, an improved model fit when using our rescaled scores in the fourth column rather than left-right distance measures based on expert data. Most importantly, the substantive effect is stronger for the rescaled scores than for the original distance variable. An increase in the left-right distance between a voter and a previously supported governing party is positively related to an individual's probability to defect from this party. On the basis of model 3 with the original coding, we simulate a $3.7 \%$ increase in the defection probability $(95 \% \mathrm{CI}:-1.7,+9.7)$ when we change the left-right distance from the $5^{\text {th }}$ to its $95^{\text {th }}$ percentile while fixing all other variables at their mean. Thus, we cannot rule out the null hypothesis. On the other hand, when we calculate a first difference on the basis of model 4 with rescaled scores, we simulate a $6.3 \%$ increase in the defection probability $(95 \% \mathrm{CI}:+2.3,+11.0)$. Not only is this effect statistically significant, its magnitude is estimated to be more than $70 \%$ larger when using rescaled scores

Table 4 Explaining government defection in the 2009 European elections

\begin{tabular}{|c|c|c|c|c|}
\hline & $\begin{array}{c}\text { Hobolt, Spoon } \\
\text { and Tilly (1999) } \\
\text { (1) }\end{array}$ & $\begin{array}{c}\text { Hobolt, Spoon } \\
\text { and Tilly (2004) } \\
\text { (2) }\end{array}$ & $\begin{array}{c}\text { Benoit/Laver } \\
\text { (2009) } \\
(3)\end{array}$ & $\begin{array}{c}\text { Rescaled } \\
\text { scores (2009) } \\
\text { (4) }\end{array}$ \\
\hline Distance left-right & $\begin{array}{c}0.02 \\
(0.03)\end{array}$ & $\begin{array}{l}0.15^{* * * *} \\
(0.03)\end{array}$ & $\begin{array}{c}0.04 \\
(0.03)\end{array}$ & $\begin{array}{l}0.14 * * * \\
(0.05)\end{array}$ \\
\hline Distance EU & $\begin{array}{c}0.04 \\
(0.02)\end{array}$ & $\begin{array}{l}0.05^{* *} \\
(0.02)\end{array}$ & $\begin{array}{c}0.02 \\
(0.02)\end{array}$ & $\begin{array}{c}0.02 \\
(0.02)\end{array}$ \\
\hline Age & $\begin{array}{c}-0.01 * * \\
(0.00)\end{array}$ & $\begin{array}{c}-0.01 * * \\
(0.00)\end{array}$ & $\begin{array}{l}0.01 * * \\
(0.00)\end{array}$ & $\begin{array}{l}0.01 * * \\
(0.00)\end{array}$ \\
\hline Social class & $\begin{array}{c}0.02 \\
(0.05)\end{array}$ & $\begin{array}{c}0.02 \\
(0.04)\end{array}$ & $\begin{array}{c}0.09 * \\
(0.05)\end{array}$ & $\begin{array}{c}0.09^{*} \\
(0.05)\end{array}$ \\
\hline Party identification & $\begin{array}{c}-0.57 * * * \\
(0.06)\end{array}$ & $\begin{array}{c}-0.63 * * * \\
(0.05)\end{array}$ & $\begin{array}{c}-0.83^{* * * *} \\
(0.06)\end{array}$ & $\begin{array}{c}-0.83 * * * \\
(0.06)\end{array}$ \\
\hline Satisfaction with economy & $\begin{array}{c}-0.14^{* *} \\
(0.07)\end{array}$ & $\begin{array}{c}-0.08 \\
(0.05)\end{array}$ & $\begin{array}{c}-0.13 \\
(0.08)\end{array}$ & $\begin{array}{c}-0.13^{*} \\
(0.08)\end{array}$ \\
\hline Government approval & $\begin{array}{c}-0.34 * * * \\
(0.11)\end{array}$ & $\begin{array}{c}-0.95^{* * *} \\
(0.09)\end{array}$ & $\begin{array}{c}-0.35^{* * *} \\
(0.10)\end{array}$ & $\begin{array}{c}-0.34 * * * \\
(0.10)\end{array}$ \\
\hline Intercept & $\begin{array}{c}0.18 \\
(0.37)\end{array}$ & $\begin{array}{c}0.01 \\
(0.31)\end{array}$ & $\begin{array}{c}-0.13 \\
(0.28)\end{array}$ & $\begin{array}{c}-0.21 \\
(0.27)\end{array}$ \\
\hline Log-likelihood & -1399 & -2147 & -1826 & -1822 \\
\hline No. of individuals & 2868 & 4824 & 3937 & 3937 \\
\hline No. of countries & 15 & 23 & 21 & 21 \\
\hline
\end{tabular}

Notes. Entires are hierarchical logit estimates with standard errors in parentheses. The first two columns reprint the results from Model 1 in Hobolt, Spoon, and Tilley (2009). Columns three and four are results of our estimation based on the 2009 EES data using either Benoit/Laver expert data (as Hobolt et al. did) or our rescaled scores to operationalize voter-party distances on the left-right dimension. $* p<0.10 ; * * p<0.05 ; * * * p<0.01$. 
compared to the conventional coding of the distance variable (the two distance variables correlate at 0.39). Thus, our results demonstrate the value of applying an easy rescaling of available data sources, as it can reduce measurement error when using voter-party distances of left-right in cross-national survey analysis.

We calculated two alternative versions of the left-right distance between a respondent and the party she voted for in the previous national election to check the robustness of our results. First, we calculated the absolute distance between a respondent's self-placement and the simple mean party placements. The first difference for this variable is an increase of $4.2 \%$ in the defection probability ( $95 \%$ CI: $-0.6 \%,+9.4 \%$ ), which is a smaller and insignificant effect compared to the rescaled scores. Second, we calculated the absolute distance between a respondent's self-placement and that respondent's perception of the party. We expect the effect for this distance variable to be comparable to our rescaled scores, because we essentially rescale the self-projections into a common scale. In fact, although the perceived distance variable correlates only at 0.33 with the rescaled distance, the first difference is a $5.9 \%$ increase in the defection probability $(95 \% \mathrm{CI}:+0.4 \%,+12.1 \%)$. Although the magnitude of this effect is not quite as large as for the rescaled scores (and the uncertainty is larger), this distance variable outperforms one based on simple party means or expert scores.

In summary, we have provided repeated evidence that rescaling voter placements of parties can provide reasonably valid left-right party placements that are comparable cross-nationally. Moreover, rescaled voter-party distances increase the model fit for an established cross-national model of government defection at European Parliament elections.

\section{Conclusion}

In this article, we introduce a new procedure designed to estimate voter and party locations across Europe on a common left-right scale using a readily available data source. Relying solely on survey data, our technique produces estimates that can be compared across countries while correcting for various issues related to scale perception differences. Standard errors of our estimates can be generated easily via the nonparametric bootstrap. Our procedure has several advantages. In contrast to expert surveys, our procedure provides party positions of a broader range of parties, specifically party positions for smaller parties that are typically excluded from expert ratings. Scholars of European politics benefit from our procedure because we provide comparable ideological positions for all European political groups within the same ideological scale, and these ideological positions of the European political groups are solely a by-product of our estimation. Furthermore, we are able to validate our estimates in multiple ways. Our estimates correlate strongly with estimates obtained via expert surveys, and estimates of the European political groups exhibit similar levels of convergent validity. Moreover, the improvement in party estimates that one gains from fixing various scale perception issues is significant-in estimating a valence model for voters and parties in the United Kingdom, our corrected estimates provide a superior model fit to party estimates obtained from simple means of voter placements, and the same is true for a cross-national model of government defection in European elections.

More generally, our technique to compare survey responses shares many similarities with other approaches that use bridging observations to link ideological spaces across different institutional contexts. In a survey context such as ours, differential item functioning via AM rescaling is relatively straightforward for parties within the same country, and for cross-national rescaling we leverage each party's affiliation to European political groups to identify a common space for the European context. In the absence of other sources of data, our approach presents a useful solution that improves on existing measures comparing left-right placements of parties and voters in Europe.

\section{Funding}

The authors gratefully acknowledge financial support from the Research Center SFB 884 on the "Political Economy of Reforms" at the University of Mannheim (project C4), funded by the German Research Foundation (DFG). 


\section{References}

Adams, J., S. Merrill, and B. Grofman. 2005. A unified theory of party competition: A cross-national analysis integrating spatial and behavioral factors. Cambridge, UK: Cambridge University Press.

Aldrich, J., and R. McKelvey. 1977. A method of scaling with applications to the 1968 and 1972 presidential elections. American Political Science Review 71(1):111-30.

Alvarez, R., and J. Nagler. 2004. Party system compactness: Measurement and consequences. Political Analysis 12(1):46-62.

Bafumi, J., and M. Herron. 2010. Leapfrog representation and extremism: A study of American voters and their members in Congress. American Political Science Review 104(3):519-42.

Bailey, M. 2007. Comparable preference estimates across time and institutions for the court, Congress, and presidency. American Journal of Political Science 51(3):433-48.

Bawn, K., and Z. Somer-Topcu. 2012. Government versus opposition at the polls: How governing status affects the impact of policy positions. American Journal of Political Science 56(2):433-46.

Benoit, K., and M. Laver. 2005. Mapping the Irish policy space: Voter and party spaces in preferential elections. Economic and Social Review 36(2):83.

. 2006. Party policy in modern democracies. London: Routledge.

Benoit, K., and G. McElroy. 2007. Party groups and policy positions in the European Parliament. Party Politics 13(1):5-28.

Bergara, M., B. Richman, and P. Spiller. 2003. Modeling Supreme Court strategic decision making: The Congressional constraint. Legislative Studies Quarterly 28(2):247-80.

Blais, A., R. Nadeau, E. Gidengil, and N. Nevitte. 2001. The formation of party preferences: Testing the proximity and directional models. European Journal of Political Research 40(1):81-91.

Brady, H. E. 1985. The perils of survey research: Inter-personally incomparable responses. Political Methodology 11(3-4):269-91.

Calvo, E., and T. Hellwig. 2011. Centripetal and centrifugal incentives under different electoral systems. American Journal of Political Science 55(1):27-41.

Campbell, D., and D. Fiske. 1959. Convergent and discriminant validation by the multitrait-multimethod matrix. Psychological Bulletin 56(2):81-105.

Carroll, R., J. B. Lewis, J. Lo, K. T. Poole, and H. Rosenthal. 2009. Measuring bias and uncertainty in DW-NOMINATE ideal point estimates via the parametric bootstrap. Political Analysis 17(3):261-75.

Dalton, R., D. Farrell, and I. McAllister. 2011. Political parties and democratic linkage: How parties organize democracy. Oxford: Oxford University Press.

De Vries, C. 2007. Sleeping giant: Fact or fairytale? European Union Politics 8(3):363-85.

Downs, A. 1957. An economic theory of democracy. New York: Harper.

Duch, R., J. May, and D. Armstrong II. 2010. Coalition-directed voting in multi-party democracies. American Political Science Review 104:698-719.

Duch, R., and R. Stevenson. 2008. The economic vote: How political and economic institutions condition election results. Cambridge, UK: Cambridge University Press.

EES. 2011. European Parliament election study, voter data, advance release (23 June 2011). www.piredeu.eu.

Efron, B., and R. Tibshirani. 1994. An introduction to the bootstrap. London: Chapman and Hall.

Egmond, M., E. Sapir, W. van der Brug, S. Hobolt, and M. Franklin. 2010. EES 2009 voter study: Advance release notes. Amsterdam: University of Amsterdam.

Enelow, J. M., and M. Hinich. 1984. The spatial theory of voting. New York: Cambridge University Press.

Erikson, R. S., and D. W. Romero. 1990. Candidate equilibrium and the behavioral model of the vote. American Political Science Review 84(4):1103-26.

Ezrow, L. 2010. Linking citizens and parties: How electoral systems matter for political representation. Oxford: Oxford University Press.

Gerber, E., and J. Lewis. 2004. Beyond the median: Voter preferences, district heterogeneity, and political representation. Journal of Political Economy 112(6):1364-83.

Golder, M., and J. Stramski. 2010. Ideological congruence and electoral institutions. American Journal of Political Science 54(1):90-106.

Groseclose, T., S. Levitt, and J. Snyder. 1999. Comparing interest group scores across time and chambers: Adjusted ADA scores for the US Congress. American Political Science Review 93(1):33-50.

Hinich, M., and M. C. Munger. 1994. Ideology and the theory of political choice. Ann Arbor: University of Michigan Press.

Hix, S., A. Noury, and G. Roland. 2007. Democratic politics in the European Parliament. Cambridge, UK: Cambridge University Press.

Hobolt, S. B., J.-J. Spoon, and J. Tilley. 2009. A vote against Europe? Explaining defection at the 1999 and 2004 European Parliament elections. British Journal of Political Science 39(1):93-115.

Hooghe, L., R. Bakker, A. Brigevich, C. de Vries, E. Edwards, G. Marks, J. Rovny, and M. Steenbergen. 2010. Reliability and validity of measuring party positions: The Chapel Hill expert surveys of 2002 and 2006. European Journal of Political Research 49:687-703.

Jessee, S. A. 2009. Spatial voting in the 2004 presidential election. American Political Science Review 103(1):59-81. 
Kedar, O. 2005. When moderate voters prefer extreme parties: Policy balancing parliamentary elections. American Political Science Review 99(2):185-99.

King, G., C. Murray, J. Salomon, and A. Tandon. 2004. Enhancing the validity and cross-cultural comparability of survey research. American Political Science Review 98(1):191-207.

Lewis, J. B., and K. T. Poole. 2004. Measuring bias and uncertainty in ideal point estimates via the parametric bootstrap. Political Analysis 12(2):105-27.

Lo, J., S.-O. Proksch, and T. Gschwend. 2013. Replication data for: A common left-right scale for voters and parties in Europe. http://dx.doi.org/10.7910/DVN/23113 (accessed November 8, 2013).

Macdonald, S. E., O. Listhaug, and G. Rabinowitz. 1991. Issues and party support in multyparty systems. American Political Science Review 85(4):1107-31.

Mair, P., and C. Mudde. 1998. The party family and its study. Annual Review of Political Science 1(1):211-29.

Markus, G. B., and P. E. Converse. 1979. A dynamic simultaneous equation model of electoral choice. 73(4):1055-70.

McElroy, G., and K. Benoit. 2010. Party policy and group affiliation in the European Parliament. British Journal of Political Science 40(2):377-98.

2012. Policy positioning in the European Parliament. European Union Politics 13(1):150-67.

McFadden, D. 1973. Conditional logit analysis of qualitatative choice behavior. In Frontiers of Economics, ed. P. Zarembka. New York: Academic Press.

Palfrey, T., and K. Poole. 1987. The relationship between information, ideology, and voting behavior. American Journal of Political Science 31(2): 511-30.

Peterson, D. A. M. 2009. Campaign learning and vote determinants. American Journal of Political Science 53(2):445-60.

Poole, K. 2005. Spatial models of parliamentary voting. Cambridge, UK: Cambridge University Press.

Poole, K. T., and H. Rosenthal. 1997. Congress: A political-economic history of roll call voting. New York: Oxford University Press.

Poole, K., H. Rosenthal, J. Lewis, J. Lo, and R. Carroll. 2011. Recovering a basic space in R. Working Paper

Powell, G. 2000. Elections as instruments of democracy: Majoritarian and proportional visions. New Haven, CT: Yale University Press.

Quinn, K. 2004. Bayesian factor analysis for mixed ordinal continuous response. Political Analysis 12:338-53.

Rabinowitz, G., and S. E. Macdonald. 1989. A directional theory of issue voting. American Political Science Review 83(1):93-121.

Rehm, P., and T. Reilly. 2010. United we stand: Constituency homogeneity and comparative party polarization. Electoral Studies 29(1):40-53.

Reif, K., and H. Schmitt. 1980. Nine second-order national elections. A conceptual framework for the analysis of european election results. European Journal of Political Research 8(1):3-44.

Saiegh, S. 2009. Recovering a basic space from elite surveys: Evidence from Latin America. Legislative Studies Quarterly 34(1):117-45.

Shor, B., C. Berry, and N. McCarty. 2010. A bridge to somewhere: Mapping state and congressional ideology on a crossinstitutional common space. Legislative Studies Quarterly 35(3):417-48.

Shor, B., and N. McCarty. 2011. The ideological mapping of American legislatures. American Political Science Review 105(3):530-51.

Treier, S. 2010. Where does the president stand? Measuring presidential ideology. Political Analysis 18(1):124.

Westholm, A. 1997. Distance versus direction: The illusory defeat of the proximity theory of electoral choice. American Political Science Review 91(4):865-83. 